\title{
How to Disagree About Argument Schemes
}

\author{
Fábio Perin Shecaira
}

Federal University of Rio de Janeiro, Faculty of Law

Rua Moncorvo Filho $n^{\circ} 8$

Rio de Janeiro

20211-340 Brazil

fabioperin@direito.ufrj.br

\begin{abstract}
Argumentation theorists often disagree about which scheme best represents a given type of argument (e.g. argument by analogy, argument from authority, inference to the best explanation). Unfortunately, these theorists sometimes become involved in fruitless pseudodisagreement because they fail to perceive that their supposedly competing schemes are means for achieving different (but compatible) practical or theoretical goals. This paper explains some of the different purposes that an argument scheme may serve, and indicates how the relevant type of pseudodisagreement may be avoided.
\end{abstract}

Résumé: Les théoriciens de l'argumentation sont souvent en désaccord sur le schéma qui représente le mieux un type donné d'argument (par exemple un argument par analogie, un argument fondé sur un appel à l'autorité, une inférence à la meilleure explication). Malheureusement, ces théoriciens s'impliquent parfois dans un pseudo-désaccord infructueux parce qu'ils ne perçoivent pas que leurs systèmes en soidisant concurrence sont des moyens d'atteindre des objectifs pratiques ou théoriques différents (mais compatibles). Cet article explique quelques-uns des différents objectifs d'un schéma d'argument et indique comment on peut éviter le type pertinent de pseudo-désaccord.

Keywords: metatheory of argumentation, uses of argument schemes, criteria for evaluating argument schemes

\section{Introduction}

An argument (or argumentation) scheme is a "representation of an argument type" (Katzav and Reed 2004, p. 249). This standard (if vague) definition indicates why debate about schemes in the informal logic literature often involves disagreement about argument taxonomy or classification. Disagreements about argument classification include disagreement about how many different types of argument there are and how they relate to one another, about whether classification should be field-dependent or "natural", pragmatic or semantic, about whether any classification can be exhaustive of possible argument types, and so on. 
In this paper, I want to focus on a very specific kind of disagreement about argument schemes. This is the kind of disagreement that takes place between authors who use the same basic categories (e.g. argument by analogy, argument from authority, inference to the best explanation) and yet disagree about which scheme best represents arguments fitting one or more of these categories. Take a widely recognized category like inference to the best explanation. The sort of disagreement I am interested in is that which may arise between authors who agree that this is a distinctive type of argument, but nevertheless disagree about just how many premises it has and what they look like, about whether the argument is made up of only one relation of implication or is rather a compound made up of a set or sequence of such relations, about what operator most adequately qualifies each relation of implication (e.g. 'probably', 'plausibly', 'presumably'), and so on.

In particular, this paper hopes to highlight the fact that authors sometimes become involved in pseudo-disagreement when arguing about which scheme best represents a given type of argument. It is my contention that authors involved in debate about argument schemes often end up arguing at cross-purposes because they fail to realize that their supposedly competing schemes are means for achieving different-but compatibletheoretical or practical ends. In Sections 3-5, I will make a case for the foregoing contention; but first I would like to explain how I came to suspect that it is true.

\section{Background}

Bruce Waller (2001) proposed the following scheme for arguments by analogy in ethics:

1. We both agree with case a.

2. The most plausible reason for believing a is the acceptance of principle $\mathrm{C}$.

3. $\mathrm{C}$ implies $\mathrm{b}$ ( $\mathrm{b}$ is a case that fits under principle $\mathrm{C}$ ).

4. Therefore, consistency requires the acceptance of $b$.

This scheme was later criticized by Trudy Govier (2002, p. 155) for failing faithfully to represent the structure of ordinary arguments by analogy:

... 'premises' (2) and (3) are not explicit in many analogy arguments, as Waller acknowledges. In fact, he acknowledges that framing the general principle, $\mathrm{C}$, is often a difficult and challenging task for those reflecting on the ar- 
gument. We accept a case (a) and the analogy between (a) and (b) is drawn in the stated argument. We have to think to come up with $\mathrm{C}$, the general principle from which both (a) and (b) are to be inferred. $\mathrm{C}$ is not something ready-made...

It struck me, upon approaching this debate, that Govier misses Waller's main point (although Waller is partly to blame for this, as he might have been clearer about that point). One plausible interpretation of Waller's account of argument by analogy attributes to him the view that arguments fitting his scheme are better than arguments by analogy that do not fit it. ${ }^{1}$ Waller, according to this interpretation, is not denying the existence in everyday reasoning of arguments by analogy that fail to include a determinate principle. Instead, he is out to highlight the flaws of such (all-too-common) arguments. The main purpose of Waller's scheme is really a normative or prescriptive one:

... in some cases we can indeed evaluate the analogical argument without ascertaining the underlying principle. But when we deal with tougher cases, that will not always be possible. If one person claims that a difference in the two cases invalidates the a priori analogical argument, and a second disputant insists that the difference is irrelevant to the force of the analogy, then resolution of that dispute may well require attempting to formulate the underlying principle. ... Without an explicit examination of why we believe we have a right to unhook ourselves from the violinist [alluding to Judith Thomson's famous analogy], the dispute is likely to gutter in conflicting 'intuitions' that are affirmed with increasing vehemence. (2001, p. 205)

Is there real disagreement between proponents of different argument schemes who have such different goals? Waller wants to explain how arguments by analogy ought to be made (in order for arguers to avoid barren conflicts of intuition), while Govier wishes to be true to how they are in fact made. It seems futile to criticize a normative account of argument for failing to be descriptively accurate if descriptive accuracy was not its ambition in the first place. (I will develop and significantly qualify this claim in Section 3, where I argue that normative accounts of argument do need to satisfy a condition of minimal descriptive accuracy.)

\footnotetext{
${ }^{1}$ I give detailed reasons for this interpretation in Shecaira (2013).
} 
To give a more personal example, I recently found myself in the middle of a similar kind of disagreement while preparing a paper for a philosophy conference. The paper was about arguments from authority in legal practice. To discuss the way in which legal actors often appeal to the authority or expertise of legal scholars, I borrowed the following scheme (Coleman 1995, p. 366):

1. A says p.

2. A is authoritative on such things.

3. So, p.

Upon seeing this scheme, some colleagues raised the objection that it was too simple. Arguments from authority, they said, depend upon further assumptions that should be included in the argument scheme as additional premises; e.g. A has not been contradicted by other authorities on the subject. Or perhaps, if adding premises is not the best way to go, some pertinent critical questions - e.g. has A been contradicted by other authorities on the subject? - should be attached to the scheme in order to highlight the possible shortcomings of arguments that instantiate it.

My reaction was to say that good arguments from authority may indeed have to address the plausibility of the relevant assumptions (whether by including additional premises or in some other way anticipating critical questions), but that one of my purposes in employing the simple scheme was precisely to show how tersely (and hence questionably) arguments from authority tend to be formulated in the legal domain. My ultimate purpose was to evaluate arguments from authority in law, but first I wished to present an accurate picture of legal practice. Consider an example of an argument from authority appearing in a prominent Canadian legal decision:

... in balancing the state's interest in the protection of the foetus as potential life under s. 1 of the Charter against the right of the pregnant woman under s. 7 greater weight should be given to the state's interest in the later stages of pregnancy than in the earlier. The foetus should accordingly, for purposes of s. 1, be viewed in differential and developmental terms: see Sumner LW (1981), Professor of Philosophy at the University of Toronto, Abortion and Moral Theory, pp 125-128.

The expert, Sumner, whose intellectual authority is implied by the presentation of his credentials, is heeded by Justice Wilson

\footnotetext{
${ }^{2} R v$ Morgentaler [1993] 3 S.C.R. 463.
} 
of the Supreme Court of Canada without any mention of whether authors with similar credentials might disagree with him. Considering how contentious the subject of abortion is among moral and legal philosophers, it is quite safe to assume that there are important dissenting voices on the issue of whether the fetus should be viewed in "differential and developmental" terms. ${ }^{3}$ Insofar as I am right to interpret the foregoing passage as containing an argument from authority, then the simple scheme is an accurate way to depict its crude structure. More developed schemes with additional premises would require attributing to Justice Wilson controversial claims or assumptions that are not even hinted at in the opinion.

So, I found myself in a position not altogether different from Waller's in respect of Govier. There Waller could have replied to Govier by arguing that his scheme was meant to serve a normative purpose, and therefore could not be faulted for being descriptively inaccurate. I, on the other hand, could reply to critics by saying that my preferred scheme was meant to serve a descriptive purpose, and thus could not be faulted for failing to show how arguments from authority should be made by legal actors. The general point, to be clear, is that the purposes or uses of argument schemes may vary significantly, and with them should vary the criteria by reference to which the schemes are evaluated. Schemes that mean to describe should be evaluated by reference to their descriptive accuracy, while schemes that do not mean to describe (or that do not mean only to describe) should be judged according to other criteria apart from (or in addition to) descriptive accuracy.

Section 3 elaborates the distinction between schemes serving normative purposes (or normative schemes) and schemes serving descriptive purposes (descriptive schemes). Section 4 explores the idea that descriptive schemes can also serve significantly different purposes depending on what exactly they mean to describe: discrete arguments or argumentative dialogues, public reason-giving or private reasoning processes. Section 5 concludes by trying to reinforce the case against optimism about "multi-purpose" schemes; i.e. schemes that get high scores along all the relevant dimensions: descriptive accuracy, normative attractiveness, and so on. To that end, I will use in Section 5 a meta-scheme for the evaluation of argument schemes proposed by Douglas Walton and Giovani Sartor (2013).

\footnotetext{
3 As Marvin Kohl (1982) points out, Sumner's view that more developed (hence more sentient) fetuses have greater moral standing should be controversial even among utilitarians like Sumner himself.
} 


\section{Descriptive schemes and normative schemes}

According to Douglas Walton et al. (2008, p. 11), "schemes are the forms of argument (structures of inference) that enable one to identify and evaluate common types of argumentation in everyday discourse." This definition might be interpreted as indicating, far too optimistically, that identification and evaluation of a common type of argument are goals that can invariably be pursued through use of a single argument scheme. Often this is not the case, and different argument schemes may be required to fulfill the different functions. J. Anthony Blair (2012, p. 143) recognized this basic point by distinguishing

between, on the one hand, a scheme that conveys the pattern of reasoning that someone actually used in a particular instance of reasoning or argument, which entails no endorsement of that reasoning or argument, and, on the other hand, a scheme that portrays a supposedly valid or cogent pattern of inference or argument. ${ }^{4}$

I will explain shortly why the distinction I want to draw is similar, but not identical, to Blair's. For now, let us focus on the idea that schemes should both help us to identify common types of argument and evaluate them. Suppose we identify an argument pattern that strikes us as fallacious. To clarify the structure of that type of argument as advanced in everyday reasoning we would need a descriptive scheme; i.e. a scheme serving to convey a pattern of reasoning as actually used. Walton et al. might argue that just by exhibiting and clarifying the structure of the flawed argument pattern, any such descriptive scheme would also help to expose its shortcomings. In that sense, a scheme may indeed be able to serve at once a descriptive and evaluative purpose. But argument evaluation is a broad notion. If we plausibly include within it the important goal of advising arguersi.e. of showing them how to adjust their arguments in order to avoid fallacies and bad reasoning in general - then we need to acknowledge that, for evaluative purposes, a different sort of scheme may often be required apart from the descriptive one. A descriptive argument scheme may help us to spot the problems in an argument pattern, but it is not (by itself) always capable of providing guidance on how to avoid those problems.

\footnotetext{
${ }^{4}$ Bart Garssen (2001) makes a similar distinction between schemes that serve as tools for identifying arguments and schemes that serve as tools for evaluating arguments. Like Blair, however, Garssen does not explore the complex relation between these two types of schemes, which is the subject of this section.
} 
Walton et al. could insist that specifically normative schemes are superfluous because the advisory role alluded to above can be played by critical questions, which they think should be attached to arguments schemes. Even when a descriptively accurate argument scheme alone is unable to guide arguers, their associated critical questions will. I will devote more space to a discussion of the function of critical questions in the next section, but a few preliminary remarks are in order. Critical questions provide a sort of checklist the use of which allows an audience to assess an argument's strength. Independently of any response from an audience, however, an arguer can also refer to and answer standard critical questions as a way of anticipating possible objections and "probing into the weak points of [the original] argument so that [she] can improve [it] by adding refinements" (Walton and Gordon 2011, p.1). Indeed, the combination of argument scheme and critical questions may provide the sort of guidance real arguers expect from argumentation theorists. It may be particularly useful for teaching argumentation and critical thinking to beginners, given the didactic value of checklists. Doubtful, however, is the idea that this advisory role would never be performed equally effectively by elaborate normative schemes unaccompanied by critical questions. ${ }^{5}$

In fact, I think this is the best way to understand the role of Waller's scheme in relation to more descriptively accurate schemes for arguments by analogy. Waller's scheme (though descriptively problematic) is supposed to serve an important prescriptive role. It is supposed to serve the role of showing us how arguments by analogy should be made; in particular, how they should be developed by the addition of premises that do not always appear in everyday analogical reasoning. Waller's scheme is supposed to play the role of showing us how arguments by analogy should be constructed in order to keep moral debate from guttering in sterile conflicts of intuitions.

This is the point at which my distinction between descriptive and normative schemes reveals itself as being different from the distinction that Blair makes in the passage quoted above. For Blair, a scheme either conveys argument patterns as they appear in actual reasoning, or it portrays them as valid or cogentvalidity and cogency pertaining, I assume, to the support that the

\footnotetext{
${ }^{5} \mathrm{I}$ am not sure if Walton et al. would disagree with me on this point. They do sometimes (2008, p. 19-20) acknowledge that scheme-plus-critical-questions compounds do not necessarily outperform normative schemes that incorporate critical questions as additional premises. However, as we will see later, the authors also say that critical questions are part of the very definition of, and are hence inseparable from, argument schemes (2008, p. 16). For the latter claim, I find no justification.
} 
premises of an argument provide for the conclusion. So, normative schemes, for Blair, are those that highlight the logical virtues of certain types of argument. Waller's scheme, however, does not focus exclusively on the validity or cogency of arguments by analogy. Waller is also interested in the dialectical advantages of arguments fitting his scheme. He claims that such arguments are less likely to result in intractable conflicts of intuition, and thus are less likely to hinder agreement.

The upshot is that, in addition to the distinction between descriptive and normative schemes, further distinctions need to be made within the latter category. (Further distinctions must also be made within the former category, but to that point I devote the whole of Section 4.) Normative schemes need to be distinguished according to whether their goal is to highlight argument patterns that are logically good, or argument patterns that are dialectically fruitful, or perhaps even argument patterns that are rhetorically effective. ${ }^{6}$ These distinctions start to give us an idea of the large number of pseudo-disagreements that may take place between argumentation theorists who advance supposedly competing schemes. In addition to pseudo-competition between normative and descriptive schemes (which is what characterizes, I think, the "Waller-Govier" debate), pseudocompetition can also take place between normative schemes that have the different but compatible goals of advising arguers about how to argue cogently ${ }^{7}$, or in ways that are conducive to rational agreement, or in ways that are rhetorically effective. To go back to Waller's scheme, one of the objections that could be made to it is that it has a redundant premise; namely, premise $1 .{ }^{8}$ Redundancy is arguably a logical defect of an argument pattern. It is not, however, necessarily a flaw from the dialectical or rhetorical point of view. Before assessing any argument scheme we

\footnotetext{
${ }^{6}$ There is evidence in the literature about the types of argument that tend to be preferred by arguers in contexts where persuasion is key. For instance, Schellens and De Jong (2004, p. 315) published a study about "which sorts of argumentation are used in persuasive public information documents", such as brochures developed by government agencies and other organizations discussing drug abuse, skin cancer, animal rights, etc.

${ }^{7}$ Theorists with this particular goal in mind might also become involved in pseudo-disagreement if they hold different conceptions of cogency and are not attentive to that fact. For instance, one may design a normative scheme on the unspoken but consequential assumption that there are only two ways in which an argument may be cogent: i.e. deductively or inductively. It is possible, but not likely, that pseudo-disagreement would arise for that reason, since theorists involved in debate about normative schemes tend to be sensitive to this particular issue; see, e.g., Hahn and Hornikx (2016, p. 1851).

${ }^{8}$ The redundancy at issue will be explained more fully in the course of this section.
} 
need to agree about the point of view from which we wish to assess it.

Now, one important point must be granted to those who might still view with suspicion the distinction between normative and descriptive schemes. Informal logic is not a discipline that prides itself on discussing arcane types of argument. Informal logic is supposed to provide tools for understanding and evaluating everyday argumentation. That being the case, there is arguably a descriptive constraint that every normative scheme must satisfy within informal logic. Within this domain, a normative scheme must teach us how to make a common type argument the best it can be (logically or dialectically or rhetorically), which means that it cannot do so by proposing adjustments so profound that they render the argument type unrecognizable. Minimal descriptive accuracy is required of every normative scheme. A normative scheme should not be deeply revisionist. ${ }^{9}$ Indeed, of all the objections that may be made against Waller's scheme for arguments by analogy, perhaps the strongest one is that it revises the familiar form of arguments by analogy to such an extent that the result hardly looks like a scheme for arguments by analogy, as opposed to a scheme for arguments from principle or something of the sort. Intuitively, an argument by analogy in ethics recommends that a case under dispute (the target-case) be treated in the same way as a similar and less contentious case (the source-case). For instance, "If smoking tobacco is deemed morally permissible, then so should smoking marijuana be deemed permissible. These practices have similar effects on the smoker's body and behavior." Whatever the merits of this argument, it is recognizable as an analogy because it recommends that the target-case (smoking marijuana) be treated like the source-case (smoking tobacco) given their similarities (with respect to health and behavior). But what if this argument were redrafted to fit Waller's scheme? The result would look something like this: "We both agree that smoking tobacco is morally permissible. The most plausible reason for this is the acceptance of the principle that it is morally permissible to smoke substances that cause no immediate health risks or antisocial behavior. This principle implies that smoking marijuana is morally permissible. Therefore, consistency requires accept-

\footnotetext{
${ }^{9}$ An anonymous reviewer reminds me that there is a second reason (apart from recognizability) for requiring minimal descriptive accuracy from normative schemes. When evaluating particular arguments given by real people we must be true to the aspirations of the arguments' authors. Adopting an evaluative scheme that distorts the argument under scrutiny (e.g. by evaluating as an abduction what was meant as an analogy) is unfair to its author, if not pointless.
} 
ing the moral permissibility of smoking marijuana." Whatever the merits of this argument, it may be argued that it is hardly an argument by analogy. What drives the argument is not the similarity between source- and target-cases. A principle comes in to justify our treatment of the source-case and entails a similar treatment of the target-case. The principle is thus placed between the two cases and, again, makes any reference to the source-case logically superfluous. ${ }^{10}$

Here is another way of looking at the problem. Nothing prevents an author who writes about a certain type of argument from working with two (or more) schemes. For instance, an account of argument by analogy may include one scheme that captures arguments by analogy as they typically appear in everyday discourse and a second scheme that serves as a recipe for arguers wishing to attain some specific logical, dialectical or rhetorical benefit. The only constraint on such accounts is that the two schemes should be sufficiently similar to be recognized as versions of the same argument type, not different argument types. I do not take up the task of giving precise general criteria for determining whether any two schemes are sufficiently similar to count as versions of the same argument type. This would, at a minimum, require a technical discussion of the nature of the warrants or implicit conditional claims associated with each scheme. But perhaps a useful heuristic is to keep in mind the categories whose distinctiveness is a matter of relative consensus in argumentation theory. When comparing descriptive and normative schemes we should think in terms of well-known classes of argument such as argument from authority, argument by analogy, inference to the best explanation, pro-and-con argument, and so on. We have cause to be suspicious whenever a normative scheme is revisionist to the point where it starts to makes arguments fitting one of these established categories look too much like arguments fitting another. That is when the normative scheme will probably fail to satisfy the condition of minimal descriptive accuracy.

One reason why I am not entirely sure whether Waller has violated this condition is that his normative scheme for arguments by analogy is not readily associated with any of the other classes of arguments with which we are familiar. If Waller had

\footnotetext{
${ }^{10}$ An anonymous reviewer argues that the first premise in Waller's scheme is not redundant, since it can be seen as support for the general principle in the second premise. I agree, but as I argued in Shecaira (2013) that entails that Waller's scheme is made up of two inferences, the general principle being derived from the source-case and subsequently applied to the target-case. I find this an interesting way of reading Waller, but it does not save him from the charge of revisionism elaborated below.
} 
made arguments by analogy look too much like inferences to the best explanation, say, then he could more confidently be accused of undue revisionism. Consider four possible schemes for arguments by analogy (where ' $A$ ' and ' $B$ ' refer to the acts or facts being compared; ' $\mathrm{X}$ ', ' $\mathrm{y}$ ', ' $\mathrm{z}$ ' are specific features of those acts or facts; and ' $W$ ' refers to ways in which the acts or facts are to be treated - e.g. as morally permissible or impermissible):

$\mathrm{A}$ is $\mathrm{W}$;

$\mathrm{B}$ is just like $\mathrm{A}$; therefore, $\mathrm{B}$ is $\mathrm{W}$.
(2)

A has $\mathrm{x}, \mathrm{y}, \mathrm{z}$;

$\mathrm{B}$ has $\mathrm{x}, \mathrm{y}, \mathrm{z}$;

$\mathrm{A}$ is $\mathrm{W}$; therefore, $\mathrm{B}$ is $\mathrm{W}$.

(4)
(3)
A has $\mathrm{x}, \mathrm{y}, \mathrm{z}$;
$\mathrm{B}$ has $\mathrm{x}, \mathrm{y}, \mathrm{z}$;
$\mathrm{A}$ is $\mathrm{W}$;
it is in virtue of $\mathrm{x}, \mathrm{y}, \mathrm{z}$, that $\mathrm{A}$ is $\mathrm{W}$;
therefore, $\mathrm{B}$ is $\mathrm{W}$.
A has $\mathrm{x}, \mathrm{y}, \mathrm{z}$;
$\mathrm{B}$ has $\mathrm{x}, \mathrm{y}, \mathrm{z}$;
$\mathrm{A}$ is $\mathrm{W}$;
all things which have $\mathrm{x}, \mathrm{y}$,
$\mathrm{z}$ are $\mathrm{W}$;
therefore, $\mathrm{B}$ is $\mathrm{W} .{ }^{11}$

I assume there would be little disagreement about the status of (1)-(3) as alternative schemes representing arguments by analogy. On the other hand, (4) may raise questions. Schemes (3) and (4) are prima facie very similar, but it could be argued that (4) actually crosses an important line, since those of its premises that refer to A (the source-case) are redundant from a logical point of view. Facts about A have no impact on the validity of arguments fitting the scheme (which means that the implicit conditional associated with this argument pattern will include no reference to the source-case). Of all four schemes, (4) is most similar to Waller's scheme-hence my doubts about Waller's revisionism.

This fourfold sample serves to shows us that there is significant leeway for revision when an author is proposing a normative argument scheme: after all, (1)-(3) are all permissible. But there are also lines that cannot be crossed. Drawing these lines precisely is a difficult task that I leave to authors engaged in the project of developing full taxonomies of argument.

\footnotetext{
${ }^{11}$ These schemes are borrowed from Govier (1989).
} 


\section{What do descriptive schemes describe?}

\subsection{Some remarks about interpretation}

Consider again Blair's distinction (to which I referred in the previous section) between "a scheme that conveys the pattern of reasoning that someone actually used in a particular instance of reasoning or argument, which entails no endorsement of that reasoning or argument" and "a scheme that portrays a supposedly valid or cogent pattern of inference or argument." It could be thought that Blair and I hold a naïve view of argument interpretation. Real arguers do not always clearly separate their premises from their conclusions (many elements of real arguments are expressed indirectly or left implicit), they do not always have precise views about the logical structure of their arguments, they often use repetition and anecdote for rhetorical effect, and so on. In other words, arguers leave out of their discourse much that is relevant from the theoretical point of view, and they include in it much that is irrelevant from that same point of view. Therefore, when argumentation theorists claim to identify, describe or convey an argument pattern used in everyday reasoning, they are

really subjecting that reasoning to a reconstruction in light of technical concepts and theories. Is this reconstruction in any way a value-driven exercise? Have Blair and I been ignoring this possibility and making a facile distinction between description and evaluation of arguments? In what follows I try to explain why the distinction between description and evaluation can be maintained, even though it has a fuzzy borderline.

M. Agnès van Rees (2001, p. 182) separates "such different, if not plainly incompatible purposes such as [i] reconstructing the beliefs the arguer had in mind, [ii] reconstructing the plausible beliefs the arguer must have had in mind, and [iii] reconstructing what the arguer is committed to by virtue of his words." Imagine that someone advances an argument including the following premise: "Politicians are all crooks". As interpreters of the argument, we must face the choice of either taking the arguer's words at face value (this is option (iii) in Rees's threefold distinction) or considering whether they are just a clumsy expression of the (more common and plausible) idea that many politicians are crooks. The fact that the statement was made in the context of a heated debate by someone who is generally known to avoid crude generalizations would allow us to presume that the arguer's real intention was to express the relatively banal idea that many politicians are crooked (heeding the arguer's intention in this way would be to take option (i)). Of course, it could be the case that the evidence of the arguer's in- 
tentions was inconclusive. Perhaps we learn that she repeated the stronger claim several times in her discourse, which gives us some reason to think that, when politics are the topic, the arguer is more willing than usual to put forward strong generic claims. If we are unsure about the arguer's intentions, the only reason not to take her discourse at face value would be to enforce some version of the principle of charity in interpretation (this, I presume, is option (ii)).

The point of this example is to acknowledge that argument interpretation is not simple. It is not clear, to begin, if interpreters should give intended meaning precedence over literal meaning whenever they are in conflict. In other words, it is not clear which interpretative strategy has priority: (i) or (iii). But even if, as interpreters, we always wanted to be true to arguers' intentions (as I think we should be), our problems would not be over. Intentions are not always plain. When they are not plain, the principle of charity is apt to be used. What must be acknowledged is that application of the principle of charity blurs the distinction between argument description and evaluation; for in using the principle, we speculate about what an arguer "must have meant" by (inter alia) dismissing that which is too implausible for the arguer to have meant. Whenever the principle is used, it should thus be used frankly and explicitly. Otherwise, the suspicion may arise that one is deliberately revising an argument or argument pattern in light of specific epistemic or logical ideals under the pretense of charitably interpreting ambiguous discourse.

Consider, for illustration of this last point, current debate about the structure of third pattern conductive arguments (or pro-and-con arguments). Carl Wellman (1971, p. 57) explained that this is a type of argument "in which some conclusion is drawn from both positive and negative considerations". One of his examples is this: "[A]lthough your lawn needs cutting, you ought to take your son to the movies because the picture is ideal for children and will be gone by tomorrow." It is tempting to represent this argument as follows:

1. Your lawn needs cutting.

2. (But) the picture is ideal for children and will be gone by tomorrow.

3. Therefore, you ought to take your son to the movies.

We might add an implicit premise to the effect that there is no time for both cutting the lawn and going to the movies, but that is beside the point. A more important objection against the foregoing representation is that it includes both pro and con consid- 
erations as premises of the argument. That is an odd thing to do considering that premises are typically defined as claims or propositions advanced in support of a conclusion. "Premise" 1 of the argument above offers no support for the conclusion; in fact, it gives a reason against the conclusion (albeit a reason ultimately defeated by the consideration expressed in premise 2).

Recognizing this problem, Hans Hansen (2011, p. 35-40) considers a number of alternative ways to represent pro-and-con arguments. One idea he rejects quite quickly is that con considerations might be part of the conclusion of the relevant argument pattern. If this were the case, then the lawn-versus-movie argument would look like this:

1. The picture is ideal for children and will be gone by tomorrow.

2. Therefore, you ought to take your son to the movies even though your lawns needs cutting.

This conception of pro-and-con argument is problematic for more than one reason, but it is instructive to focus our attention on one of the reasons why Hansen rejects it. Given that sentences of the form " $p$ even though q" imply sentences of the form " $p$ and q", the conclusion of the argument above implies both that the interlocutor ought to take his son to the movies and that his lawns needs cutting. But the second conjunct in that conclusion in no way follows from the premise, which makes the resulting argument a "very bad argument, much worse than we think it should have turned out" (ibid., p. 37). Hansen is right to say that the argument is bad. But is this any reason to deny that everyday pro-and-con arguments have the relevant structure? To avoid the risk of confusing the issue of what a certain type of argument looks like in practice with the issue of what it should look like, Hansen could defend his position by indicating more explicitly that it involves an application of the principle of charity. $\mathrm{He}$ could then say there are other ways to represent pro-and-con arguments besides the one at issue that are compatible with salient features of everyday discourse and yet are more generous to real arguers.

This shows how tricky argument interpretation can be. The point, again, is not that there is no difference between, on the one hand, seeking earnestly to describe and clarify arguments as advanced by real arguers and, on the other hand, setting out to give advice on how to evaluate and construct arguments of that type. This distinction becomes blurry only when the principle of charity is at stake. What we should do to mini- 
mize the risk of distorting an arguer's intentions is to use the principle of charity parsimoniously and explicitly. Interpreters should always avow their use of the principle, and should only use it in cases of genuine doubt about how to construe equivocal argumentative discourse. If an argument is clearly a bad one, interpreters should not revise it or improve it under the pretense of being "charitable". In the remainder of this section, I want to put the difficulties of argument interpretation to the side, and discuss the idea that interpretation may target different argumentative phenomena.

\subsection{Discrete arguments or argumentative dialogue?}

A scheme may be used to represent an argument understood as a discrete set of claims composed of premise(s) and conclusion. It may also be used to represent an argumentative exchange or dialogue characterized by the formulation of an argument (in the sense of a discrete premise(s)-and-conclusion set) followed by objections, counter-objections, requests for clarification, and so on. Why assume that any single scheme will be apt to provide a faithful representation of both arguments and argumentative exchanges of a certain type? An argument from authority, for example, is not the same as the (often protracted) exchange that begins with a discrete argument from authority (advanced by one of the interlocutors) and then develops through a series of questions, clarifications, objections, replies, etc. Why assume that the same scheme for argument from authority will do a good job of representing both phenomena?

According to Walton et al. (2008, p.16), 'critical questions form a vital part of the definition of a scheme'. I disagree. Critical questions are not part of the very definition of a scheme, although they might be an important part of a particular kind of schemes, namely, those that have as their object argumentative exchanges (as opposed to discrete arguments). If Walton et al. think critical questions are a necessary part of argument schemes this is probably because they understand the very notion of a scheme by reference to the role it plays in argumentative exchanges. As Walton has put it in a more recent essay coauthored with Sartor (2013, p. 115), "[b]y producing an argument fitting a scheme, a side shifts a burden of proof to the other side, in a dialectical exchange of arguments and questions." It may well be true that critical questions should be attached to schemes that intend to represent the burden-shifting dynamic that characterizes argumentative exchanges. But what if that is not what a particular account of argument hopes to achieve? 
Argumentation also takes place outside contexts of real dialogue. When a court gives an argument for a ruling, for example, it leaves the parties little room for questions, objections, and counter-arguments. Typically, the parties only have a chance to make their cases prior to the ruling. They may be able to appeal, but eventually a judicial decision will settle the case. The idea that legal argumentation can be depicted as a dialogue is not altogether false, but it can be very misleading. Advocates exchange arguments in relatively dynamic fashion only in prototypical adversarial systems, but even there they would have limited opportunity to counter the court's reasoning. Legal argumentation does not always occur between equal parties with ample space for dialogue. The law is characterized by formality, hierarchy, authority, and a strong institutional incentive toward settlement. $^{12}$ In making reference to Sumner, for example, Justice Wilson advanced a terse argument from authority that could certainly be improved. Additional premises could be added to the argument, critical questions might be tackled — but these are all possible improvements. A scheme that portrays how the court really argued in that case would have to be a simpler scheme. A reader of the court's judgment might also use critical questions to guide her own, private assessment of the court's reasoning; but, again, these critical questions should not figure in a depiction of the argument as given by the court.

The upshot is that we may need different schemes depending on whether we want to talk about arguments or argumentative exchanges. To be clear, our decision to discuss one or the other is not a matter of sheer choice or stipulation. Moves of the type, "let us imagine that arguments are dialogues..." should be viewed with suspicion in some contexts. Our schemes should be tailored to the specific phenomena we are analyzing. In some social contexts people give arguments but they do not necessarily engage each other as genuine interlocutors. Schemes that fail to indicate this fact are not faithful representations of the practices at issue.

${ }^{12}$ I think Walton and Sartor (2013, p. 134) overstate their point when they say that "judicial argument can be seen as part of a persuasion dialogue, inspired by the need to come to a shared view of the law, where the parties, as well as other judges and citizenry, are invited to accept the motivation put forward by the judge." I would not deny that judges often seek social legitimacy. But even if this renders judicial argument to some extent dialogical, in the sense that it makes judges responsive to the expectations of their audience, it would be going too far to suggest that judges typically interact with parties and other judges (and citizenry!) in a type of dialogue best represented by a scheme that includes critical questions. 
I have been contrasting schemes that simply distinguish premise(s) and conclusion to schemes that also include critical questions - the former being prima facie better candidates for the representation of discrete arguments, and the latter being prima facie better candidates for the representation of argumentative exchanges. But these are not the only types of schemes that purport to represent everyday argumentation. What about Toulmin-type schemes, with their distinctive concepts of warrant, backing, rebuttal, etc., which are supposed to be more "elaborate or candid" (Toulmin 2003, p. 89) than standard premise(s)-and-conclusion schemes? According to Bart Verheij (2006, p. 181), Toulmin thought that "arguments need to be analyzed using a richer format than the traditional one of formal logic in which only premises and conclusions are distinguished." Whether or not this is an accurate characterization of Toulmin's position, we should regard with suspicion the idea that arguments need, as a general matter, to be analyzed with Toulmin-type schemes. Again, we should ask for what purposes such schemes are more adequate than the alternatives. For showing how arguments are advanced in practice? But argumentative practices vary significantly. Some practices involve dialogue, while others do not. Some involve arguers arguing candidly, while others involve arguers using terseness as a rhetorical device, or even confused arguers using underdeveloped arguments. ${ }^{13}$ Do we not need different types of schemes to represent these different argumentative phenomena?

\subsection{Public argument or private reasoning?}

The arguments we make public with the goal of engaging our interlocutors do not always reflect the less straightforward and less tidy process through which our mind tends to take us as we develop our ideas and consider their plausibility in light of available evidence. Consider, for instance, our common attempts to achieve reflective equilibrium in our moral beliefs. We move back and forth, rather unsystematically, from general moral principles to our judgements about particular cases, trying to make sure that the principles are mutually compatible (or, even better, mutually reinforcing) as well as not over- or underinclusive with respect to the real or hypothetical cases that concern us. We may begin the process with certain principles in mind and certain intuitions about concrete cases that we will

\footnotetext{
${ }^{13}$ See Vorobej 1991, p. 112, for the concept of an embryonic argument, that is, an argument given by an individual who does not have precise beliefs about the character of the logical link between premises and conclusion.
} 
significantly revise or utterly abandon eventually. But if, at the end of the process, we decide to write an ethics paper, we are not likely to formulate our argument in a way that represents all the details of our reasoning. That argument could be too long and complicated and interesting only as a piece of intellectual biography. The moral arguments we end up giving tend to be simpler. They advance a principle, or a set of principles, as being not only plausible in the abstract but also compatible with common intuitions about particular cases. The sort of argument I have in mind might fit something like the following scheme:

1. Principle $\mathrm{C}$ is part of a coherent set of plausible moral principles D, E, F, etc.

2. Principle $\mathrm{C}$ entails plausible recommendations about how to treat cases $a, b$, c, etc.

3. Therefore, Principle $\mathrm{C}$ is a moral principle that we should adopt.

In our paper we would naturally take time to explain each premise: why $\mathrm{C}$ is part of a plausible and coherent set, why a, b, c, etc. are important cases to discuss, why $\mathrm{C}$ deals adequately with them, and so on. But we would probably not describe the tortuous path taken, through the consideration of various competing principles, before arriving at $\mathrm{C}$. We would only do so if, again, we thought this were of some biographical or perhaps didactic relevance (imagine a teacher delaying her final answer to a moral problem in order to allow students to experience the principletesting process themselves).

The point is that argument schemes should be expected to differ significantly depending on whether their goal is, on the one hand, to represent arguments as they usually appear in public debate, or, on the other hand, to give a fuller picture of the complex mental process that tends to precede the act of giving a public argument. Let me give a further illustration of this point by mentioning potential controversies about how to represent inferences to the best explanation (IBE).

Giovanni Tuzet (2014, p. 129-136), in a discussion about abduction and IBE, refers to Edgar Allen Poe's famous tale, The Murders in the Rue Morgue. In that tale, a detective investigates a case involving the brutal murder of two women (one of whom was strangled and forced up a chimney!). The abnormal strength of the perpetrator and other peculiarities of the case (e.g. the events took place in a fourth-story apartment locked from the inside and the perpetrator was heard from outside the apartment by witnesses who could not agree about which language he spoke) lead the detective to suppose that the killer might not 
even be human. To test this hypothesis, the detective places an ad in the newspaper inquiring if anyone had lost an orangutan in the region. A sailor comes forward and ends up admitting that his orangutan had indeed escaped, climbed the victims' building and attacked them.

Tuzet argues that the detective realizes more than one inference. He abduces a hypothesis about the perpetrator being an orangutan on the basis of partial evidence, and then tests that hypothesis by means of a process that may involve other types of inference, including deduction and induction. Tuzet's explanation of the detective's process is illuminating. Yet, at the same time, I am partial to something like the following scheme for IBE:

1. There is a set of facts $\mathrm{F}$ in need of explanation.

2. Hypothesis $\mathrm{H}$ explains $\mathrm{F}$.

3. No other hypothesis explains $\mathrm{F}$ better than $\mathrm{H}$.

4. Therefore, $\mathrm{H}$ is true.

This scheme represents inference to the best explanation as a containing just one logical step, not two or more. It is not clear that Tuzet has any room in his account for such a scheme. But is the scheme inadequate for representing the detective's reasoning in Poe's tale? It is and it is not-everything depends on what exactly the scheme is supposed to reveal. It is inadequate as an attempt to represent the way in which the orangutan hypothesis was originally formed in the detective's mind and later ingeniously tested. But suppose the detective (or an advocate in his stead) were to do what we expect him to do at the end of the reasoning process, namely, present his evidence to the authorities in order to show them what really happened to the victims in the Rue Morgue. Given the goal, at this point, of giving evidence for his findings (not simply telling his story or explaining his process), we would expect the detective to argue along these lines:

1. There is a set of facts in need of explanation, namely, two women were killed by an agent of abnormal strength, who spoke an unintelligible dialect, in an inaccessible apartment locked from the inside, the building being in an area where an orangutan was let loose, etc.

2. The hypothesis that the aforementioned orangutan killed the victims explains all the foregoing facts.

3. No other hypothesis (e.g. that the victims were killed by a thief) does a better job of explaining those facts. 
4. Therefore, the hypothesis that the orangutan killed the victims is true.

The fact that there was orangutan in the area where the events took place is part of the evidence given by the detective in support of his conclusion. Never mind that this fact was only established after the detective first envisaged the hypothesis that the killer might be an orangutan. This chronological fact, interesting though it may be, has no clear evidential or justificatory importance.

\section{Conclusion}

Walton and Sartor (2013, p. 121-123) give an interesting analysis of teleological schemes for reasoning towards practical decisions:

1. I (an agent) have a goal G.

2. Carrying out this action $\mathrm{A}$ is a means for me to realize $\mathrm{G}$.

3. Therefore, I ought (practically speaking) to carry out this action $\mathrm{A}$

This scheme is accompanied by a set of five critical questions, including: "What other goals do I have that should be considered that might conflict with my goal G?", "What alternative actions to my bringing about $A$ that would also bring about $G$ should be considered?", and "Among bringing about A and these alternative actions, which is arguably the most efficient?" According to Walton and Sartor, the scheme can be used to discuss a variety of subjects, including the justification of argument schemes themselves. For example,

1. I have a goal of getting beliefs that are as true as possible, in matters pertaining to my choices.

2. Carrying out the action consisting in executing the scheme "argument from expert opinion", whenever this scheme is relevant, is a means to realize the goal of getting beliefs that are as true as possible, in matters pertaining to my choices.

3. Therefore, I ought (practically speaking) to carry out the action consisting in executing the scheme "argument from expert opinion", whenever this scheme is relevant. 
Critical questions associated with this particular argument would include, among others: "What other goals do I have that should be considered that might conflict with my goal of getting beliefs that are as true as possible in matters pertaining to my choices?", "What alternative actions to executing the scheme 'argument from expert opinion' that would also bring about that goal should be considered?", and "Among executing the scheme 'argument from expert opinion' and these alternative actions, which is arguably the most efficient?"

For our purposes, a useful way to apply Walton and Sartor's teleological scheme would be to replace the variable A with the action of executing some particular scheme for an argument type, selected among competing schemes for that same argument type. We might, for instance, try a teleological justification of Waller's scheme for arguments by analogy. Arguably, the relevant goal $\mathrm{G}$ would not be getting beliefs that are as true as possible, but rather (or also) increasing the likelihood of agreement in exchanges where arguments by analogy appear. The argument would naturally be open to the critical question whether some other goal does not conflict with that of agreement. Another important critical question would be whether there are any other schemes in the literature (perhaps the sort of scheme preferred by Govier) that could more effectively serve the goal of enhancing the likelihood of agreement. And so on.

To be clear, I am not suggesting that the teleological justification of particular argument schemes (like Waller's scheme for argument by analogy) must be evaluated according to Walton and Sartor's particular scheme for teleological arguments. One may wonder if Walton and Sartor's really is the best scheme for building a teleological argument about other argument schemes. I accept Walton and Sartor's scheme provisionally because it allows me to highlight the central message of this paper.

Walton and Sartor's scheme for teleological reasoning helps us to see how the defense of any particular argument scheme must be relative to the goals of the scheme's promoter. These goals, to recapitulate, may include describing an argument type as typically advanced or guiding arguers towards better reasoning. In addition, they may involve the analysis of discrete arguments or argumentative exchanges, public reasongiving or private reasoning processes. Only once we have a definite goal in mind among the various possibilities (and confidence in its compatibility with other worthwhile goals), may we begin to compare our preferred scheme with the alternative schemes in the literature. Otherwise, we run the risk of wasting our time in pseudo-disagreement. 
Acknowledgements: For helpful comments and discussion, I would like to thank Pat Bondy, Luís Duarte d'Almeida, Ben Hamby, Katharina Stevens, and two anonymous reviewers for Informal Logic. My research has been supported by the Brazilian National Council for Scientific and Technological Development $(\mathrm{CNPq})$.

\section{References}

Blair, J. Anthony. 2012. Groundwork in the theory of argumentation. Selected papers of J. Anthony Blair. Dordrecht: Springer.

Coleman, Edwin. 1995. There is no fallacy of arguing from authority. Informal Logic 17 (3): 365-383.

Garssen, Bart. 2001. Argument schemes. In Crucial concepts in argumentation theory, ed. Frans H. van Eemeren, 81-99. Amsterdam University Press.

Govier, Trudy. 1989. Analogies and missing premises. Informal Logic 11 (3): 141-152.

Govier, Trudy. 2002. Should a priori analogies be regarded as deductive arguments? Informal Logic 22 (2): 155-157.

Hahn, Ulrike and Jos Hornikx. 2016. A normative framework for argument quality: argumentation schemes with a Bayesian foundation. Argumentation 193 (6): 1833-1873.

Hansen, Hans. 2011. Notes on balance-of-consideration arguments. In Conductive argument. An overlooked type of defeasible reasoning, eds. J. Anthony Blair and Ralph Johnson, 31-51. College Publications.

Katzav, J. and C.A. Reed. 2004. On argumentation schemes and the natural classification of arguments. Argumentation 18 (2): 239-259.

Kohl, Marvin. 1982. L.W. Sumner's Abortion and Moral Theory. International Studies in Philosophy 18 (3): 101-102.

Rees, M. Agnès van. 2001. Argumentation interpretation and reconstruction. In Crucial concepts in argumentation theory, ed. Frans H. van Eemeren, 165-199. Amsterdam University Press.

Schellens, Peter Jan and Menno De Jong. 2004. Argumentation schemes in persuasive brochures. Argumentation 18 (3): 295323.

Shecaira, Fábio. Analogical Arguments in Ethics and Law: A Defence of a Deductivist Analysis. Informal Logic 33 (3): 406-437

Toulmin, Stephen. 2003. The uses of argument. Updated edition. Cambridge University Press. 
Tuzet, Giovanni. 2014. Usos jurídicos de la abducción. In Prueba e Razonamiento Probatorio en Derecho, eds. Juan Amado e Pablo Bonorino, 121-147. Granada: Editorial Colmares.

Verheij, Bart. 2006. Evaluating arguments based on Toulmin's scheme. In Arguing on the Toulmin model. New essays in argument analysis and evaluation, eds. David Hitchcock and Bart Verheij, 181-202. Springer.

Vorobej, Mark. 1992. Defining deduction. Informal Logic XIV (2\&3): 105-118.

Waller, Bruce. 2001. Classifying and analyzing analogies. Informal Logic 21 (3): 199-218.

Walton, Douglas, Chris Reed and Fabrizio Macagno. 2008. Argumentation schemes. Cambridge University Press.

Walton, Douglas and Thomas Gordon. 2011. Modeling Critical Questions as Additional Premises. In Argument Cultures: Proceedings of the 8th International Conference of the OSSA, ed. Frank Zenker, 1-13. Available at:

http://www.dougwalton.ca/papers $\% 20 \mathrm{in} \% 20 \mathrm{pdf} / 11$ OSSA.pdf

Walton, Douglas and Giovanni Sartor. 2013. Teleological justification of argumentation schemes. Argumentation 27 (2): 111-142.

Wellman, Carl. 1971. Challenge and response. Justification in ethics. Southern Illinois University Press. 